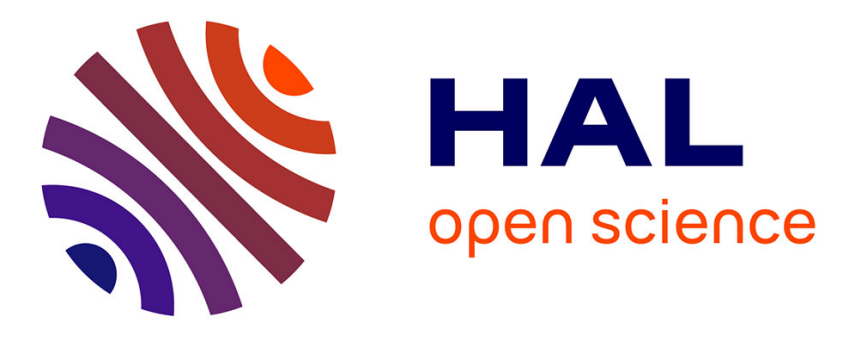

\title{
Does Virtual Reality Affect Visual Perception Of Egocentric Distance?
}

Thomas Rousset, Christophe Bourdin, Cedric Goulon, Jocelyn Monnoyer, Jean-Louis Vercher

\section{- To cite this version:}

Thomas Rousset, Christophe Bourdin, Cedric Goulon, Jocelyn Monnoyer, Jean-Louis Vercher. Does Virtual Reality Affect Visual Perception Of Egocentric Distance?. 2015 IEEE VIRTUAL REALITY CONFERENCE (VR), 2015, 10662 LOS VAQUEROS CIRCLE, PO BOX 3014, LOS ALAMITOS, CA 90720-1264 USA, Unknown Region. pp.277-278. hal-01436018

\section{HAL Id: hal-01436018 https://hal.science/hal-01436018}

Submitted on 15 May 2018

HAL is a multi-disciplinary open access archive for the deposit and dissemination of scientific research documents, whether they are published or not. The documents may come from teaching and research institutions in France or abroad, or from public or private research centers.
L'archive ouverte pluridisciplinaire HAL, est destinée au dépôt et à la diffusion de documents scientifiques de niveau recherche, publiés ou non, émanant des établissements d'enseignement et de recherche français ou étrangers, des laboratoires publics ou privés. 


\title{
Does Virtual Reality really affect visual perception of egocentric distance?
}

\author{
Thomas Rousset ${ }^{1} \quad$ Christophe Bourdin ${ }^{1} \quad$ Cédric Goulon ${ }^{1} \quad$ Jocelyn Monnoyer $^{2} \quad$ Jean-Louis Vercher $^{1}$ \\ 1. Aix Marseille Université, CNRS, ISM UMR 7287, 13288, Marseille, France. 2. PSA Peugeot Citroën, Velizy Villacoublay
}

\begin{abstract}
Virtual reality (driving simulators) tends to generalize for the study of human behaviour in mobility. It is thus crucial to ensure that perception of space and motion is little or not affected by the virtual environment (VE). The aim of this study was to determine a metrics of distance perception in VEs and whether this metrics depends on interactive factors: stereoscopy and motion parallax. After a training session, participants were asked, while driving, to estimate the relative location ( 5 to $80 \mathrm{~m}$ ) of a car on the same road. The overall results suggest that distance perception in this range does not depend on interactive factors. In average, as generally reported, subjects underestimated the distances whatever the vision conditions. However, the study revealed a large interpersonal variability: two profiles of participants were defined, those who quite accurately perceived distances in VR and those who underestimated distances as usually reported. Overall, this classification was correlated to the level of performance of participants during the training phase. Furthermore, learning performance is predictive of the behavior of participants.
\end{abstract}

Keywords: Driving simulation, distance perception, stereoscopy, parallax, variability.

Index Terms: J.4 [Computer Applications]: SOCIAL AND BEHAVIORAL SCIENCES-Psychology; I.3.7 [3D Graphics and Realism]: Virtual Reality.

\section{INTRODUCTION}

One of the major problems encountered in driving simulators concerns perception of distances in virtual environments (VE). It is generally established that distances are misperceived in VEs and suggested that this misperception consists, among other things, in a compression of egocentric distances [1][2].

Even if these observations have been made many times for many different types of VR systems [3][4], the origin of this perceptual difference in VEs relative to reality still remains not clearly explained. Many potential factors have been studied, i.e. graphic resolution [5], width of field of view [6], linear perspective [7] and contrast of the scene [8]. The way the threedimensional (3D) aspect of the simulated environment is rendered seems to deserve special attention. We recently obtained preliminary data suggesting the impact of stereoscopy and parallax in a task of emergency braking in a driving simulator. These preliminary data showed that the presence of these depth cues could significantly affect distance perception in virtual environments. The aim of the present study was to establish a metrics of distance perception in virtual environments and whether this metric depends on interacting factors (stereopsis and motion parallax) involved in the perception of distances.

\section{Method}

We tested distance perception from 5 to $80 \mathrm{~m}$. A driving simulator device was inserted into a virtual reality immersive CAVE (Fig. 1 left). Road environment was simulated in two parts with the ICE software. It consisted of a straight road with two lanes. Participants, seated in a bucket seat, were equipped with 3D glasses and targets for head position tracking (ART). The car cabin was always simulated with $3 \mathrm{D}$, parallax and stereoscopy, whereas the external environment was rendered in graphic 3D, but either with or without stereoscopy and parallax.

The participants drove a car initially stationary on the right lane, and were instructed to drive toward a static vehicle and shift on the left lane to overtake it. When arriving at a varying distance from the static vehicle $(5,10,20,40,50,60,70$ or $80 \mathrm{~m})$, this one disappeared. Participants were required to continue to drive straight ahead, by maintaining speed, and press a button on the steering wheel when they believed their car was aligned with the static vehicle. To minimize the possibility of using spatial cues during the pointing task, shaders were respectively applied to the texture of the road, to the roadside grass and to side walls. The VE was designed to allow the subjects to build a metrics of the external environment during the first half of the trial (Fig 1, center), and then to improve speed perception (by the generation of a visual flow) without presenting cues for spatial positioning during the second half of a trial (Fig 1, right). The first part of the trial consisted in the acceleration phase of the subjects from 0 to $60 \mathrm{~km} / \mathrm{h}$, whereas the second part consisted in a driving phase at constant speed $(60 \mathrm{~km} / \mathrm{h})$. Four conditions were tested:

- Control condition (CC) equivalent to the current state of a static simulator (without parallax and stereoscopy on the external environment);

- Parallax Condition (PC), with parallax on the external scene but no stereoscopy;

- Stereoscopic Condition (SC), with stereoscopy but no parallax - Total Condition (TC) with parallax and stereoscopy on the external scene.
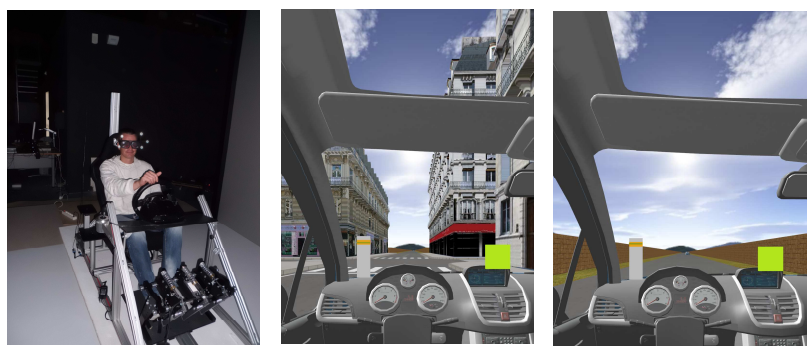

Figure 1: Left: The driving simulator in operation. Center: screenshot of the first part of the simulated environment (urban street). Right: Screenshot of the second part of the simulated environment (field road).

Male (17) or female (11) young drivers with no prior experience in immersive VR setups were tested. Before starting the experimental sessions, each participant performed a training phase in order to stabilize his/her driving performance. This phase 
ensured that all subjects understood the task requirements and adopted a reproducible driving behavior. It consists in two blocks of 20 trials without parallax or stereoscopy on the external scene. In the first block, the static car remained visible throughout the trial (closed-loop) whereas it disappeared (open-loop) as in the experimental session for the last 20 trials. The dependent variable was the error (in $\mathrm{m}$ ) between the positions of the two cars at the moment the participant pressed the button.

\section{Results}

Repeated measures ANOVA with group as categorical predictor showed a lack of significant effect of condition on performance $(\mathrm{F}=0.520 ; \mathrm{p}>0.05)$ suggesting that the visual conditions did not affect perception of distances.

Results showed a global underestimation of distances (average relative error: $15.03+/-16.64 \mathrm{~m}$ ) as usually observed in VE. However, this underestimation was accompanied by huge interindividual variability. Then, we tested the possibility of the presence of two typical profiles distinguished by the patterns of errors. A hierarchical ascending classification (HAC) by Ward's criterion showed that it was possible to classify the sample of subjects into two distinct categories based on the relative error (Figure 2). On this basis, we assigned a group to the different subjects according to this classification. Subjects of group 1 did not underestimate distances between $5 \mathrm{~m}$ and $60 \mathrm{~m}$ and were accurate in the perceptual task (in average, perceptual errors was $2.62+/-10.29 \mathrm{~m})$, whereas subjects of group 2 strongly underestimated the distances (in average $27.45+/-11.85 \mathrm{~m}$ ).

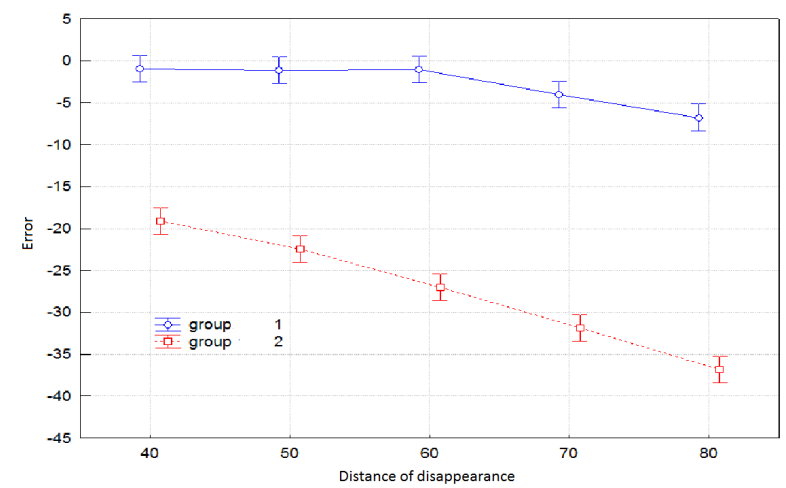

Figure 2: Mean error for both groups on 5 distances of disappearance.

To investigate a possible source of idiosyncrasy, we analyzed behavior and performance during training sessions. In particular, we characterized the level of learning by comparing the error at the end of the initial closed-loop block with the error at the end of the open-loop block. Figure 3 shows that a differentiation between both groups of subjects clearly exists as soon as the end of the training phase. The position of each point (corresponding to an individual participant) on the graph shows the error generated by the disappearance of vehicle. The more points are taken away from the $\mathrm{X}$ axis, the more this error is high. Subjects from group 1 perform much less errors during training, and their performance improvement is higher than subjects from group 2 .

\section{Discussion}

Two phenomena are highlighted by the results of this study: 1) the lack of significant effect related to the vision condition and 2) the identification of two types of behaviors, which directly depend on idiosyncratic characteristics of the participants: subjects who learned the best during the training phase, that is to say those who have taken advantage of the closed loop visual phase to improve their performance in open loop, exhibited the best ability to judge distances during the experimental session. Overall, we demonstrated that performances observed during the training phases allow predicting, to some extent, what will be the behavior of the drivers during the experimental phase. Indeed, this particular point could be a very innovative solution to the recurring problem of misperception of distance for all studies in VR. It raises the question of the necessary presence and quality of prior familiarization phase before any study conducted in a driving simulator, this phase allowing furthermore to select the "best" subjects, that is in this particular case, those who have during the virtual simulation the nearest perception to real conditions perception.

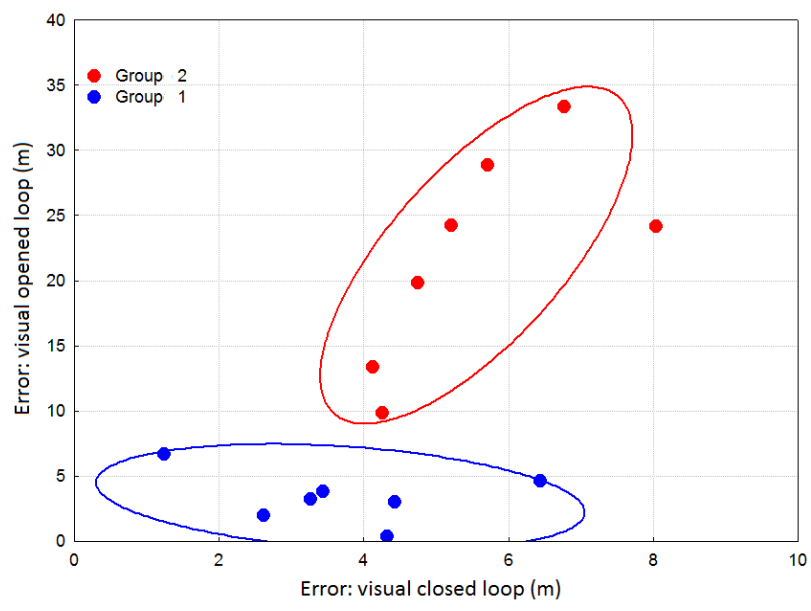

Figure 3: relative performance of participants during the initial open-loop training block (X axis) and the final open-loop block ( $\mathrm{Y}$ axis). Red points for group 1 and blue point for group 2 .

\section{References}

[1] D. Henry and T. Furness. Spatial perception in virtual environments: Evaluating an architectural application. In Proceedings of the IEEE Conference - Virtual Reality Annual International Symposium (VRAIS) '93. Seattle WA, pages 33-40. 1993.

[2] B. G. Witmer and P. B. Kline. Judging perceived and traversed distance in virtual environments. Presence: Teleoperators and Virtual Environments 7(2), pages 144-167. 1998.

[3] J. M. Plumbert. And al. Distance Perception in Real and Virtual Environments. ACM Transactions on Applied Perception, 2(3), pages 216-23. 2005.

[4] J. Bergeron and al. urban transportation and the environment in the 21st Century, Wit Transactions On The Built Environment, 89, pages 431-437. 2006.

[5] V. Interrante and al. Distance perception in immersive virtual environments, revisited. Proceedings IEEE Virtual reality Conference. 2006.

[6] J. M. Knapp and J. M. Loomis. Limited field of view of headmounted displays is not the caus of distance underestimation in virtual environments. Presence, 13, pages 572- 577. 2004.

[7] R. T. Surdick and al. The perception of distance in simulated visual displays: A comparison of the effectiveness and accuracy of multiple depth cues across viewing distances. Presence: Teleoperators and Virtual Environments, 6(5), pages 513-531. 1997.

[8] R. G. Eggleston and al. Virtual reality system effects on sizedistance judgements in a virtual environment. In Proceedings of the IEEE Conference - Virtual Reality Annual International Symposium (VRAIS) '96. Santa Clara, CA, pages 139-146. 1996. 